\title{
Bridging Aficionados' Perceptual and Conceptual Knowledge to Enhance How They Learn from Experience
}

\author{
KATHRYN A. LATOUR \\ MICHAEL S. LATOUR
}

\begin{abstract}
The aficionado consumer is one who consumes and enjoys a hedonic product regularly but has failed to obtain product expertise from his/her many experiences. We conceptualize the aficionado as having asymmetric perceptual and conceptual knowledge and posit that when these two types of knowledge are bridged with a sensory consumption vocabulary, the aficionados are better able to learn from their experiences. In experiment 1 , we find that providing aficionados a cross-modal learning tool (wine aroma wheel) during their tasting helps them strengthen their experiential memory and withstand influence from misleading marketing communications. We also find that when aficionados are presented with a misleading consumption vocabulary during their tasting, they more readily accept the marketing misinformation that results in memory distortion. In experiment 2 , we find that accurate multisensory information delivered through either the wine aroma wheel or advertising can enhance how aficionados learn from their direct tasting experience.
\end{abstract}

I can certainly see you know your wine. Most of the guests who stay here would not know the difference between Bordeaux and Claret. (Basil Fawlty [John Cleese] in Fawlty Towers; "Claret" is an English term for Bordeaux.)

$\mathrm{W}$ hile there has been research comparing novice and expert decision makers in the way they learn from marketing communications (e.g., Alba and Hutchinson 1987), there has been surprisingly little research on consumers inbetween these two states. We define aficionados as those who consume a product frequently and are enthusiastic about it

Kathryn A. LaTour is associate professor of hospitality marketing in the William F. Harrah College of Hotel Administration, University of Nevada, Las Vegas, NV 89154 (kathryn.latour@unlv.edu). Michael S. LaTour is professor and Beam Research Fellow, Department of Marketing, College of Business, University of Nevada, Las Vegas, NV 89154 (michael.latour@ unlv.edu). The authors thank the editor, associate editor, and reviewers for their helpful comments and Bill Messier for comments on an earlier draft of this article. The authors would like to acknowledge financial assistance for this research project from the William F. Harrah College of Hotel Administration at the University of Nevada, Las Vegas, as well as the generous wine donation from Wirtz Beverage Group of Nevada. Thanks also to Ann Noble, who allowed us to purchase her wine aroma wheels at a discounted price. We are grateful to Gael Hancock for her copyediting assistance.

John Deighton served as editor and Steve Hoch served as associate editor for this article.

Electronically published June 8, 2010 but who have not obtained the highly developed product schemata and lexicon associated with expertise. For example, these aficionado consumers, like the John Cleese character, may enjoy drinking claret but do not necessarily have the conceptual knowledge to realize that claret and Bordeaux wine are one and the same.

The lack of attention paid to these consumers is surprising, given that they account for a large market for hedonic products - it has been estimated that for wine, the aficionado accounts for about a third of the total market (Lockshin and Spawton 2001). If the path from novice to expert just involved more consumption, then the omission of aficionados might not be so problematic. However, we believe learning about complex hedonic products like wine involves acquiring different types of knowledge that develop at different rates. Aficionados may go on for years drinking wine without learning from their experiences unless they activate and use conceptual knowledge to help them encode and retain their experiences in memory.

We turn to the verbal overshadowing literature from cognitive psychology as a starting point for investigating how knowledge asymmetries affect memory of a perceptual experience (Melcher and Schooler 1996). That research stream suggests aficionado consumers may be more susceptible to having their experiences influenced by verbalization attempts (than novices or experts) because of their greater perceptual than conceptual knowledge. However, that re- 
search also suggests that when perceptual and conceptual knowledge are aligned, experiential learning is more likely to occur. In our research, we posit that bridging the perceptual/conceptual knowledge gap with language tools is critical for aficionados' ability to learn from their experiences.

Conceptual knowledge consists of general knowledge about the product category as well as concrete sensory descriptions about product characteristics. Returning to our John Cleese example, while knowing that claret is the same as Bordeaux wine may make him appear more knowledgeable about wine to his guests, that type of general knowledge is not going to help in his ability to learn from his tasting experience. We suggest that acquiring concrete sensory language that allows aficionados to integrate their perceptual and conceptual knowledge and extract more information from their direct experience is important in their development of expertise. In two experiments, we investigate ways in which aficionados can transform their experiential learning: (1) using a cross-modal tool that helps them convey their sensory experience into words and (2) exposing them to multisensory advertising that can help provide language to interpret their experiences.

\section{CONCEPTUAL BACKGROUND}

In addressing the multidimensional nature of consumer knowledge, Park, Mothersbaugh, and Feick (1994) distinguish product usage frequency (perceptual knowledge) from general knowledge of the product category (conceptual knowledge). Expert consumers are high in both types of knowledge; novice consumers are low in both. There are two distinct views that address how consumers become experts: one is the "perfect world" hypothesis in which increased product usage alone would eventually lead to expertise; the other advocates that more directed study is needed (see Hutchinson and Eisenstein 2008).

For complex sensory hedonic products like wine, the "perfect world" hypothesis is unlikely to hold. Wine can be experienced and enjoyed without the consumer learning detailed conceptual knowledge of the product. For example, early research in consumer involvement (Zaichkowsky 1985) found no significant correlation between product involvement with red wine and objective knowledge $(r=-.08)$.

Demonstrating that the aficionado consumer has differing levels of knowledge is the first step for addressing how they may better learn from their direct product experiences. We therefore present a preliminary study replicating and extending Melcher and Schooler's (1996) work on verbal overshadowing. Verbal overshadowing occurs when postexperience verbalization impairs perceptual memory. While the preciseness of language has been implicated in the verbal overshadowing process, it has not been tested for directly. Lawless (1984) found that novices and experts differed in the type of vocabulary they used in describing wines. Specifically, he found that experts used significantly more concrete and less abstract terms than did novices. A concrete term refers to a term for which a specific sensory reference could easily be found (pineapple, lemon, yeasty). Likewise, Chollet and Valentin (2000) report that the majority of terms generated by experts are technical and precise terms, whereas novice descriptions tend to include a majority of global terms, such as "tastes good."

According to the verbal overshadowing hypothesis, experts' perceptual memory would not be affected by postexperience verbalization because they have the language abilities to properly describe their perceptual experience (e.g., Johnson and Russo 1984). Novices have neither perceptual nor conceptual knowledge, so it is unlikely that they will have the experience or the language in which to describe (or inappropriately describe) their perceptual experience (e.g., Miyake and Norman 1979). Aficionados who have much product experience will have had exposure to language terms to describe wine. However, because of their lack of conceptual knowledge, their language for describing the wine will be ineffective and can be a source of misinformation, which impairs their memory (Melcher and Schooler 1996).

\section{PRELIMINARY INVESTIGATION}

\section{Method}

Sample. One hundred and fifty consumers between the ages of 21 and 87 were recruited from the University of Nevada, Las Vegas, and community to participate in our study. We ran two experimental conditions (control, postexperience verbalization). We followed Melcher and Schooler's (1996) categories for novices, aficionados (or what they call "intermediates"), and experts.

Stimuli. We worked with a master sommelier in the selection of our test wine and testing instrument. Our test wine was a California zinfandel. The final recognition test included five samples - the original zinfandel and then four versions of the same wine, varying on levels of sweetness added (simple syrup).

Procedure. Participants were instructed how to professionally taste wine $\mathrm{X}$ without swallowing (like a sommelier). As per Melcher and Schooler (1996), participants were given this instruction: "Describe this wine precisely and in as much detail as you can. Describe it uniquely, so that someone else would match it to your description. Consider all elements of the wine's taste, smell, feel, or related associations." They were given 5 minutes to write down their description. Participants in the control conditions proceeded to a puzzle without writing down any description. The recognition test was given to all participants. Five wines were situated on a placemat, each having different letters underneath. Participants were asked to identify wine $\mathrm{X}$ by the letter underneath the glass. They then answered questions regarding their background experience with wine and took a wine quiz (from Melcher and Schooler 1996).

Coding. Two judges read the written descriptions of the wine tasting and coded for the number of words written and 
the number of concrete sensory descriptor terms used. The interrater reliability of the judges was .90 , and disputes were settled through discussion.

\section{Results}

The verbal overshadowing literature predicts that aficionados will be the most influenced by their own verbalization, with novices and experts not affected. Figure 1 contains the accuracy results by expertise; statistics appear in the figure note. The aficionados experienced the traditional verbal overshadowing effect where their own language harmed identification.

The verbal overshadowing research has not specifically investigated how the type of language used in the postexperience verbalization relates to memory accuracy, which we report in table 1 . The experts wrote the most and used the most specific sensory terms, and this was found to be positively associated with their accuracy. The aficionados' terms were not as specific and negatively associated with their accuracy. The novices did not write very detailed notes, and there was no association between what they wrote and their accuracy. These findings highlight the importance of having a developed sensory lexicon for retaining perceptual memories.

\section{Discussion}

The purpose of this preliminary investigation was to demonstrate that because aficionados have differential perceptual and conceptual knowledge, their experiential memories are malleable. Consistent with past literature, our preliminary investigation found the aficionados were most influenced by their own verbalizations, and that occurred because what they wrote was not specific enough or concrete enough to help their memory identification. While prior research in verbal overshadowing had implicated vocabulary as a factor in memory accuracy, our preliminary study directly tested and found evidence for that link. We now move forward to addressing how language can be used to bridge aficionados' experiential learning.

\section{The Whorfian Hypothesis}

The power of language to influence how an experience is perceived is based on an idea forwarded by Whorf (1956), who suggested that humans view the world organized by their linguistic system rather than their objective perceptual lenses. This hypothesis is particularly relevant for considering how aficionados learn about sensory-driven hedonic products (Hoegg and Alba 2007). Hedonic products cannot be judged solely on objective attributes and require more holistic processing (Hirschman 1980). Sensory hedonic products fit into what Hoch and Deighton (1989) describe as an ambiguous product experience because the experience itself is not completely revealing and can be potentially interpreted in multiple ways.

Language's ability to mislead aficionados' memory iden-
FIGURE 1

VERBAL OVERSHADOWING

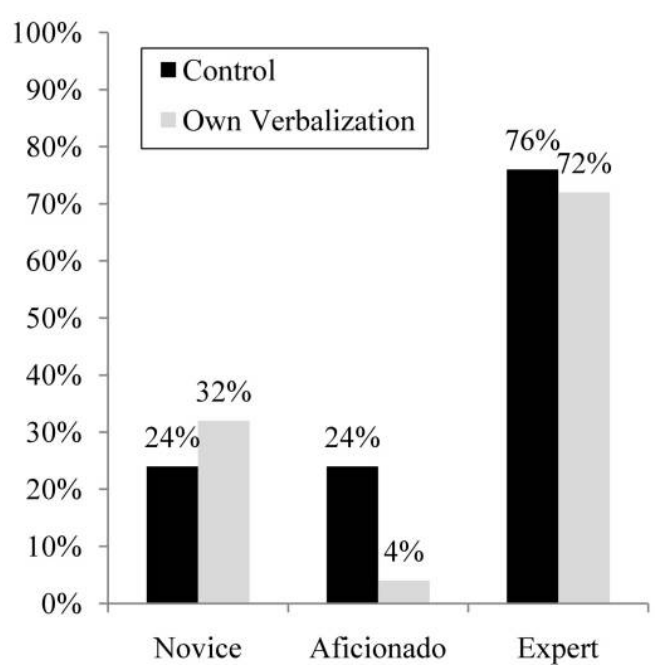

NotE.-We first compared overall accuracy by expertise, and that model was significant at $\chi^{2}(2, N=150)=41.5, p=.0001$. We then compared accuracy within each level of expertise. For novices, accuracy between the control and the write-down-experience conditions did not vary significantly ( $24 \%$ control vs. $32 \%$ write-down, $\left.\chi^{2}<1\right)$. For experts, accuracy was also similar across the control $(76 \%)$ and write-down-only $(72 \%)$ conditions $\left(\chi^{2}<1\right)$, again suggesting no overshadowing. The aficionados experienced the traditional verbal overshadowing effect, where their own language harmed identification (4\% accuracy in the write-down-only condition vs. $24 \%$ in the control condition, significantly different at $\left.\chi^{2}(1, N=50)=4.2, p=.04\right)$.

tification within the verbal overshadowing paradigm is demonstrative of the Whorfian hypothesis. Within marketing, language from postexperience advertising has been found to influence consumers' recognition memory of their sensory product experiences (Braun 1999). In these cases, language can be used to mislead or interrupt consumers' ability to learn from experience, as evidenced by their poor memory performance.

However, language can also be beneficial to consumer learning. Melcher and Schooler (2004) speculate and find some evidence that conceptual learning might reduce any potential effects of postexperience verbalization because it helps consumers develop a proper vocabulary. They also find that overshadowing is most likely to occur with consumers who have not developed an adequate vocabulary. Shapiro and Spence (2002) found that providing consumers with a consumption vocabulary during an auditory experience made them less susceptible to later misinformation. West, Brown, and Hoch (1996) suggest that acquiring a consumption vocabulary can instill more analytic processing and attention to details.

According to West et al. (1996), the consumption vocabulary can be as simple as learning the product features for a category. In wine and other sensory hedonic product experiences, there are two types of conceptual knowledge a consumer might obtain: one is more general knowledge terms for differentiating products-for instance, consumers 
TABLE 1

DESCRIPTIVE SENSORY VOCABULARY BY LEVEL OF EXPERTISE

\begin{tabular}{|c|c|c|c|c|}
\hline & Overall terms & Specific sensory terms & $\begin{array}{l}\text { Correlation between } \\
\text { overall terms and } \\
\text { accuracy }\end{array}$ & $\begin{array}{c}\text { Correlation between } \\
\text { sensory terms and } \\
\text { accuracy }\end{array}$ \\
\hline Novice & 16.8 & 3.4 & -.02 & -.03 \\
\hline Aficionado & 22.3 & 5.3 & -.44 & -.38 \\
\hline Expert & 28.4 & 9.2 & .36 & .37 \\
\hline
\end{tabular}

NoTE.-We ran a GLM (general linear model) with expertise as the independent variable and number of words and sensory terms as the dependent variables; both models were significant $(F(2,74)=6.4, p=.002$ for words; $F(2,74)=15.3, p<.0001$ for sensory terms). Experts wrote significantly more than the novices, but not the aficionados; however, for sensory terms, the experts were found to have written significantly more than both the aficionados and the novices. We ran a heterogeneity of regression test with expertise as the independent variable, accuracy as the dependent variable, and number of words and descriptors as covariates (separately) and found that in both cases, the interaction was significant $(F(2,74)=4.37, p=.01$ for number of words, and $F(2,75)=3.16, p=.05$ for number of descriptors/adjectives). These results directly link language with memory accuracy (inaccuracy).

can learn brand and attribute information. But for sensory products, the vocabulary can become experiential, where the language is used to convey different sensory aspects of the product, for instance, "tastes like cherries," "smells like grass," or "feels like butter." We follow the view of Shapiro and Spence (2002), that for sensory-driven product experiences, research on consumers' general knowledge about brands and attributes may not suffice in providing insight into how consumers learn from experience.

\section{Overcoming Overshadowing: Bridging Perceptual and Conceptual Knowledge}

One of the advantages in separating conceptual from perceptual knowledge is that it identifies opportunities for ways that aficionado learning can be enhanced. While aficionados may have learned some basic likes/dislikes and category norms through their frequent consumption, what they lack is the consistent interplay between perceptual and conceptual knowledge that experts have enjoyed, so they may act more like novices in their ability to learn from experience. For example, in our preliminary investigation, the aficionados fared no better than the novices in their memory identification when no postexperience verbalization occurred. Consumers often fail to learn from their experiences due to time pressure, distraction, and/or memory load (Hutchinson and Alba 1991). According to Mitchell and Dacin (1996), novice consumers' knowledge is primarily episodic, and consumers must actively interpret their experiences in order to form generalized knowledge. Aficionados who consume wine for pleasure may not be motivated under normal circumstances to make the perceptual/conceptual links between their experience and the prior knowledge necessary for learning to occur.

Sommelier training programs focus on enhancing sensory training by increasing perceptual abilities through standardized tasting techniques accompanied by general knowledge regarding the product characteristics. Knowledge about sensory characteristics in the product (such as grape or stylespecific sensory properties) enhances flavor detection and discernment in the experts' tasting experience (Hughson 2003). For example, when tasting a cabernet sauvignon, an expert may search for notes of bell pepper, a feature typical of wines of that grape. According to Solomon (1997), the acquisition of wine expertise entails a movement from more perceptually to more conceptually driven recognition of feature salience.

Most wine researchers recognize that sommeliers are experts of sorts, endowed with a remarkably dense lexical system (Goode 2007). Goode $(2007,89)$ argues that learned high-level cognitive processes, such as linguistic evaluation, help sommeliers to "recruit more brain areas to help with a complex task. Experienced wine tasters pull in new brain areas to help with the analysis of sensory stimuli." Our preliminary investigation found experts used more specific sensory terms in their tasting notes, resulting in higher memory accuracy (than novices or aficionados). According to Hope and Patoine (2009, 74):

One of the main differences between a sommelier and a novice concerns the expert's capacity to arrange and normalise his sensory experience through linguistic and cognitive operations, a task demanding that he focuses his attention on specific aspects of his activities. This most likely could, but does not, take place in the novice. This focusing or piloting of attention determines in part the actual conscious experience we have of this activity and can be facilitated by structured language.

\section{EXPERIMENT 1}

In this experiment, we directly test for the Whorfian hypothesis on the aficionados using the postexperience advertising paradigm. Enhancement in consumer experiential learning is observed by the aficionados' ability to disregard postexperience advertising in their memory judgments (and their inability to learn through memory distortion).

We provide some aficionados with a cross-modal sensory tool-a wine aroma wheel—which has been developed to give consumers sensory language to help their encoding of their wine-tasting experiences (Noble et al. 1987). Using several senses to encode the perceptual experience ought to develop a stronger memory trace of their experience (Guo 
and Guo 2005). In addition, the wine aroma wheel affords consumers the opportunity for forward and backward integration of their knowledge, helping to supply them with an inner dialogue that allows learning to occur (Einhorn and Hogarth 1987). Such a cross-modal tool can act like a consumption vocabulary, directing them to notice key features in their experience (West et al. 1996).

We also present some misleading cross-modal sensory terms to a group of aficionados during their product experience that are congruent with the advertising misinformation they later receive about the wine. In that situation, we would expect the aficionados to encode their experience to be consistent with that misleading vocabulary, which would lead to confirmation-seeking from the postexperience advertising (Deighton 1984).

\section{Method}

Sample. One hundred and twenty-five aficionados (similar to those used in the preliminary study) were recruited from the community via advertising in the local paper as well as posters in wine shops and e-mails to members of wine clubs. This group represented diverse backgrounds (bankers, bus drivers, singers, etc.), but all had a common interest and consumption of wine (on average, they have been drinking wine for 17 years, 15 times a month). No one had formal training with wine or worked with wine as part of his/her job. A 2 (encoding language: wine aroma wheel, misleading marketing information) $\times 2$ (advertising, not) between-subjects design was used. A control condition that did not receive any language at encoding or the advertising was used for baseline measures.

Stimuli. The same wine and recognition tests from the preliminary study were used. An advertisement was developed, intended to be misleading about the sweetness of the wine. The headline read: "X zinfandel. X's only sweet red. France meets California in a splendid offering for those who want the benefits of red wine, without the dryness. Enjoy it with a healthy meal." We adapted reviews from wine magazines to focus on the sensory aspects of the wine. One description read: "We give it a 93. X has a good sugar to acid balance, as well as being very fruit friendly. Red cherry, blackberry, crème de cassis, and licorice in aroma and taste."

Procedure. As the participants tasted wine X, they received either the wine aroma wheel, inaccurate marketing information, or no information. For the wheel presentation, the moderator explained that this wheel was used within the wine industry to help consumers translate their tasting experience into words and that the wheel also featured common descriptor terms associated with zinfandel, such as "berry, black pepper, raisin, soy, butter, vanilla." None of these terms reflect the sweetness of the wine that is suggested in the misleading advertising. For the inaccurate marketing vocabulary, participants were told that the winemaker had described the wine in the following manner: "A sweet, not dry, medium-bodied zinfandel with red cherry aroma, and crème de cassis and licorice flavors." Those given the wheel, or inaccurate vocabulary, during their tasting were encouraged to write down and describe their experience with the wine. After completing an exercise intended to clear shortterm memory, participants received the advertising (or not, in the control conditions). All participants later completed the same memory identification task described in the preliminary study.

Measures. In the postexperience advertising literature, it is proposed that the advertisement sways recognition in the direction of the ad's words (in this case, toward a sweeter wine). The recognition test was five wine samples with varying degrees of sweetness. The letters were converted to numbers for the analysis, with higher numbers associated with more sweetness and therefore more influence of the advertising (and because each varied as to the same degree of simple syrup, we felt this could be considered an interval scale for analysis, per Braun [1999]).

We developed a memory consistency measure that assesses the degree of change from their initial description to after the advertising is received, what West et al. (1996) refer to as test/retest reliability in preferences. Two independent judges coded the tasting notes for terms used in the initial and later descriptions, the overall number, and how many of the terms appeared in both descriptions. Their interrater reliability was .94 .

\section{Results}

Role of Vocabulary on Memory Identification. See figure 2 for the means and statistics. As expected, those who received the inaccurate information that was consistent with the advertising were more swayed by the advertising in their recognition compared to those who received the wheel and the advertising (significantly different in post hoc tests). Notice also that having a more accurate vocabulary (with the wheel) enhances encoding and later recognition, compared to the condition that received misleading vocabulary (significantly different in post hoc tests). The inaccurate vocabulary itself resulted in overshadowing on recognition, and receiving the ad magnified its impact.

Memory Stability. We wanted to see whether the vocabulary terms helped aficionados develop a stronger memory for the wine, so we compared the number of terms used in the encoding description that appeared in their recall statements and divided that by the total number of terms used in their recall statements, so that a 1 would indicate no change between these measures and 0 would indicate no similarity between them. We found the overall model significant at $F(3,99)=15.4(p<.0001)$, advertising not significant at $F(1,99)=2.9(p=.08)$, encoding significant at $F(1,99)=37.8(p<.0001)$, and the interaction significant at $F(1,99)=5.4(p=.02)$. The means are as follows: .90 wheel/advertising, .88 wheel/no advertising, .56 inaccurate vocabulary/ad, and .72 inaccurate vocabulary/no ad. Receiving the advertising after the inaccurate vocabulary 
FIGURE 2

EXPERIMENT 1 AFICIONADOS' MEMORY RECOGNITION

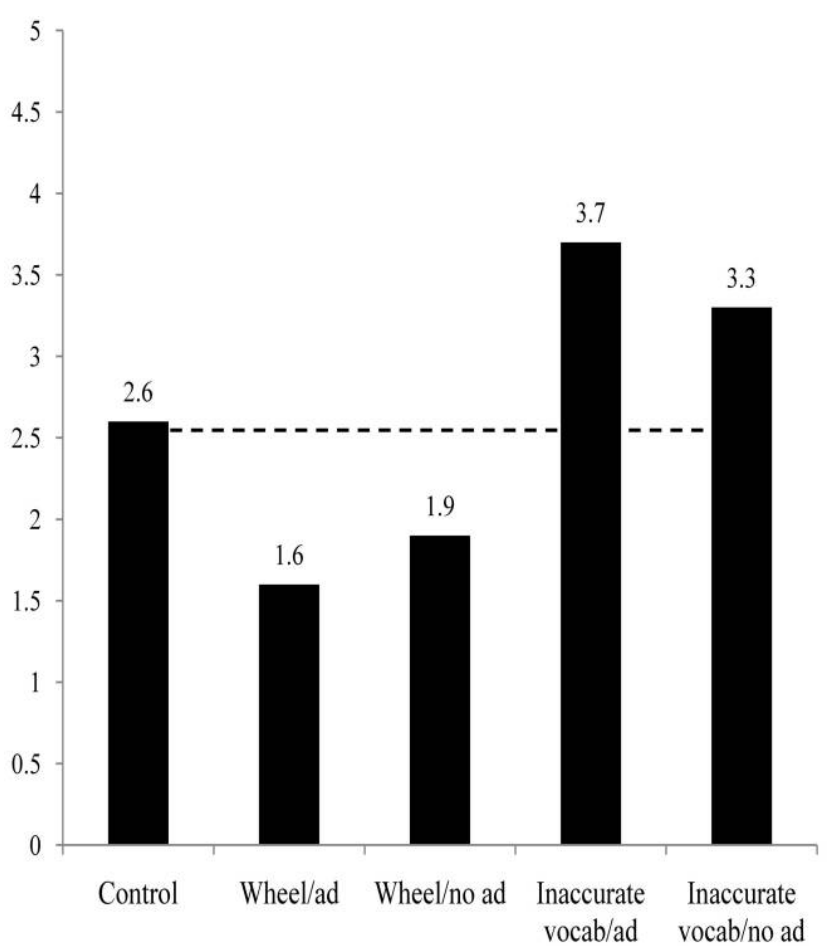

NOTE.-Higher values indicate more memory distortion (and lower values indicate greater accuracy). We ran ANOVAs with type of language present at encoding (wheel/accurate, inaccurate vocabulary) and advertising (received, not) and their interaction as factors. The overall model was significant at $F(3,99)=23.5(p<.0001)$, type of encoding instructions was significant at $F(1,99)=64.2(p<.0001)$, and the interaction was significant at $F(1,99)=$ $5.6(p=.02)$.

led to even greater incorporation of the advertising, which resulted in a less consistent memory (that condition was significantly lower than the others in post hoc tests).

\section{Discussion}

This experiment demonstrates how specific sensory terms can either enhance learning or sway learning for aficionados. One participant said about the wheel, "It helped you find the flavor you are thinking of like name recognition"; another said, "It gave me the words to use for the wine-tasting experience; it forces you to choose words to associate with the wine." The language in that case was helpful for later memory identification, as it helped them use existing conceptual knowledge to better make sense of their direct experience. However, if the inaccurate vocabulary was presented, participants also found it helpful for their encoding; for instance, one wrote: "It was helpful to know how the producer described the wine so that I could look for those aspects in my taste experience." Aficionados do not yet have the ability to distinguish a good consumption vocabulary from a bad one.
Enhanced learning from experience was demonstrated through resistance to postexperience advertising and greater memory stability. In our next experiment, we are interested in whether what appears to be greater learning with the wheel can translate into a situation where they have to discriminate their tasting experience from other types of wine (rather than just differentiating sweetness). We also consider whether such learning can also occur with multisensory advertising that accurately conveys specific sensory information. We compare these more sensory-driven language conditions to a baseline condition and a general knowledge conceptual condition.

\section{EXPERIMENT 2}

In this experiment, we look at the effectiveness of different learning tools on enhancing aficionados' sensory discrimination of wine. According to Hoch (2007), one advantage of having a developed consumption vocabulary is that it allows people to make more fine-grained distinctions among similar objects. Because each wine varietal contains different sensory characteristics, we posit that cross-modal information that highlights the sensory aspects of the wine using accurate multisensory language will enhance learning, as evidenced by greater accuracy and discrimination.

Other consumer researchers suggest that multisensory advertising can get consumers to appreciate and like their taste experiences more (Elder and Krishna 2010), but research has not yet investigated its effectiveness on guiding consumer learning accuracy. We believe that just as drama advertising has been found to draw consumers in and transform their product experience (Deighton, Romer, and McQueen 1989), multisensory advertising can instigate the consumers' dramatic experience_-pulling them into the product, having them note certain sensory aspects, and encouraging the interplay between conceptual and perceptual knowledge to enhance their experiential learning. In addition, this experiment attempts to more directly bridge the consumption vocabulary and persuasion literatures by demonstrating that advertising that provides meaning to the sensory language and experience is necessary to promote enjoyment and satisfaction.

\section{Method}

Sample. Eighty-seven participants were recruited in a similar manner to experiment 1 and represented a diverse sample from the community. On average, this group has been drinking wine for 17 years, 13 times a month, and, similar to the previous aficionados, this group did not have any formal wine training. These participants were randomly assigned to one of four conditions: control, advertising, aroma wheel, or general knowledge conceptual group.

Stimuli. A zinfandel was chosen as the target wine. The memory identification test involved having participants identify that wine from four other varietals (all Californian reds_-pinot noir, merlot, cabernet sauvignon, syrah). For the identification task, the test wines were served in colored 
TABLE 2

EXPERIMENT RESULTS BY LEARNING CONDITION

\begin{tabular}{|c|c|c|c|c|}
\hline & Conceptual test & Sensory language test & Discrimination score & Attitude \\
\hline Baseline & 3.1 & 1.6 & .04 & 5.6 \\
\hline Conceptual/general knowledge & 5.4 & 1.9 & .59 & 5.6 \\
\hline Multisensory advertising & 3.6 & 4.0 & 1.4 & 7.1 \\
\hline Wine aroma wheel & 4.0 & 6.1 & 2.6 & 5.4 \\
\hline
\end{tabular}

NotE.-Using a GLM (general linear model) with condition as the factor for the conceptual test- the model was significant at $F(3,86)=6.6(p<.0005)$; post hoc comparisons using the Dunnett procedure found that only the conceptual group was significantly higher than the control condition. For the sensory language test, the model was significant at $(F(3,85)=8.74(p<.0001)$, and both the advertising and the aroma wheel conditions were significantly different from the control (but not from each other). With the discrimination score as the dependent variable and experimental condition as the independent variable, we found the overall model significant at $F(3,86)=6.3(p=.0007)$, and both the advertising and the aroma wheel conditions were significantly higher than the control (and the wheel was significantly higher than the advertising condition). With attitude as the dependent variable and experimental condition as the independent variable, the overall model was significant at $F(3,86)=3.9(p=.01)$, and only the advertising group was found to be significantly different from the control.

glasses so that participants would be forced to focus on the taste and smell rather than color for identification.

The advertising was written to convey accurate sensory information about the wine, developed from the winemaker's description, professional reviews, and consult with a sommelier. It focused on the fig aroma and taste as well as other fruit flavors and "smooth" mouth feel. This ad used professional reviews to convey the information with positive ratings (over 90), such as this one: "While Fig Newtons were on the nose, they are not in the flavor of the wine. The figs are more concentrated, similar to fig preserves or even pickled figs. Seriously, this wine is fig-tastic; more than any other red wine we've tasted, we give it a 93." The aroma wheel session consisted of training with the wheel and was accompanied by having participants sample several aromas associated with zinfandels overall (vanilla and pepper) as well as aromas specific to this particular wine (fig, cherry, blackberry, toffee, and mocha). The general knowledge conceptual group was given a printed 12-slide PowerPoint handout describing general information about red wines, background about zinfandels in particular, the target wine's vineyard and history, and some generic language terms (such as "balance," "tannin," and, discussed earlier in this article, the term "claret" for Bordeaux blend). A one-page image of the vineyard and brand name of the wine was developed for the baseline/control group.

Procedure. The session began with participants being exposed to different material based on their experimental condition, and they were encouraged to use that information as they tasted the target wine and were asked to write down their thoughts during that tasting. They then had a short break to get some food (intended to clear short-term memory as well as their palette). When they returned, they saw five samples of wine and were told that one of those samples represented the wine they had tasted earlier, and they were to taste all five samples, indicating with each sample their confidence that that sample represented the wine they had tasted earlier. After tasting all five samples, they were asked to identify the target wine. They then proceeded to more questions about the wine, evaluated it on a number of attitude measures, provided background information about their wine consumption, and took a wine quiz.

Measures. For each of the wines in the memory identification, participants rated their confidence that it matched the earlier wine on a scale where $1=$ definitely not the wine tasted earlier, $4=$ just guessing, and $7=$ definitely the wine tasted earlier (from Melcher and Schooler 1996). A discrimination score was computed by taking their confidence rating for the actual wine subtracted by the average of their confidence for the other wines, so that a perfect discrimination score would be 6,0 means no discrimination, and a negative number means that there was a false alarm in recognition - that one of the distracter wines was rated with more confidence than the actual wine. Participants were then forced to choose one of the five wines to represent their earlier tasting (and this was used for an accuracy measure).

Participants rated their liking of the wine and likelihood to purchase on six 10-point scales, with higher values indicating more favorable ratings. These items loaded on one factor, with Cronbach's $\alpha=.97$, and were averaged to form an attitude measure. A wine test was developed to determine whether the manipulations were successful-testing whether the information delivered in the background knowledge conceptual group had been learned. We also had participants list the number of sensory descriptors associated with zinfandel as an indication that the sensory conditions (ad/ wheel) were successful in teaching sensory language.

Manipulation Test. The general knowledge conceptual group scored higher overall on the conceptual test (see means in table 2). The wine aroma wheel and multisensory advertising group participants listed the most concrete sensory terms associated with zinfandel.

\section{Results}

Discrimination. See table 2 for the means and statistics. Both the wine aroma wheel and the advertising participants were better able to discriminate the zinfandel from the other red wines, compared to the control and the general knowledge conceptual participants. 
Accuracy. When forced to make a choice in their identification, we found that participants in the advertising and the wine aroma wheel conditions were significantly more accurate than participants in the control and the general knowledge conceptual groups (see fig. 3 for the means and the statistics).

Attitude. While the wine aroma wheel may help enhance learning, evaluative information is needed for consumers to grasp how the sensory language relates to overall product evaluation, and this is best done through marketing communications. We found that attitudes were more positive in the advertising condition (see table 2 for the means and the statistics).

\section{Discussion}

The purpose of this experiment was to demonstrate that both the wine aroma wheel and multisensory advertising could enhance aficionado learning from experience by providing accurate sensory language. We found that to be the case-however, the wine aroma wheel was more effective than the advertising in promoting that learning. Given the highly involved wine aroma wheel learning session compared to the one-page advertisement, this is not particularly surprising. What is more novel is that general knowledge and language regarding wine (conceptual knowledge) did not positively enhance consumer learning. The correlation between conceptual knowledge on the wine test and overall accuracy was $r=-.05$.

We also found that advertising was informative for forming evaluative judgments about the sensory properties of the wine and for influencing overall attitude development. Therefore, it is important for hedonic brands to not only promote learning but also guide that learning by providing meaning to the sensory language and experience through marketing communications.

\section{GENERAL DISCUSSION}

\begin{abstract}
When it comes to wine I tell people to throw away the vintage charts and invest in a corkscrew. The best way to learn about wine is the drinking. (Alexis Lichine)
\end{abstract}

The Lichine quote above represents the "perfect world" hypothesis regarding familiarity and development of expertise. Unfortunately, that view does not hold in the case of a sensory-driven hedonic product like wine. For instance, in experiment 1 , we had an aficionado who had been drinking wine with dinner every night for the past 20 years, but when he was exposed to misleading advertising, it altered his memory judgment to be consistent with that communication. Treating knowledge acquisition in the "perfect world" manner misses opportunities for enhancing consumer learning.
FIGURE 3

EXPERIMENT 2 AFICIONADOS' ACCURACY BY LEARNING CONDITION

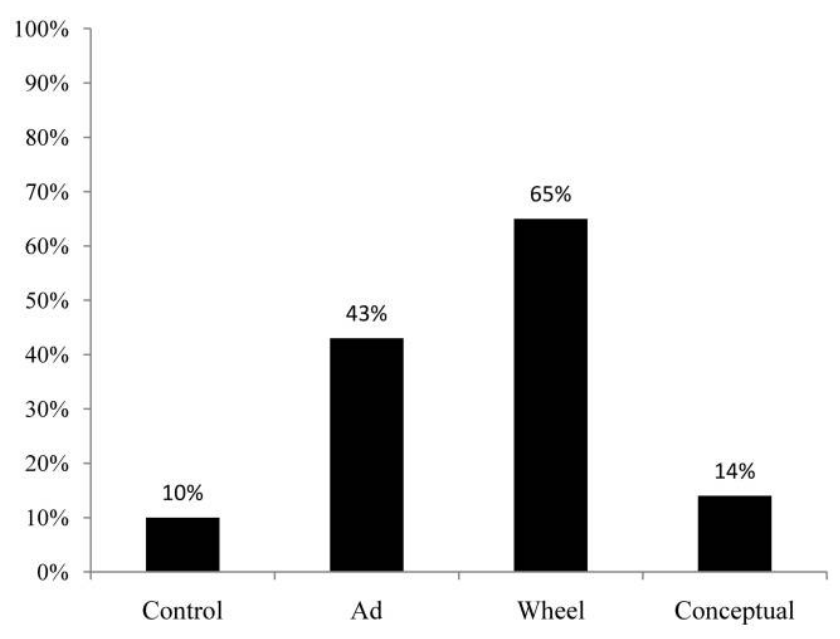

Note.-The overall model was significant at $\chi^{2}(1, N=87)=22.1, p<$ .0001 ; comparisons found advertising to be significantly different from the control $\left(\chi^{2}(1, N=43)=5.9, p=.01\right)$ and the conceptual $\left(\chi^{2}(1, N=44)=4.5\right)$ groups, but the wine aroma wheel group appeared to be much more accurate than the advertising group, which was not significant $\left(\chi^{2}(1, N=46)=3.2\right.$, $p=.07)$. The conceptual group was not significantly different from the control $\left(\chi^{2}<2\right)$. The wine aroma wheel was significantly different from both the control $\left(\chi^{2}(1, N=43)=15.6, p<.0001\right)$ and the conceptual group $\left(\chi^{2}(1\right.$, $N=44)=13.7, p=.0002)$.

If you can't describe it in words and talk about it, like "It reminds me of gym socks or my grandmother's blackberry pie" you can't remember it. (Karen MacNeill)

MacNeill's quote better describes what aficionados need to do if they want to learn from their direct product experiences. Her view is also consistent with the Whorfian hypothesis, reflecting the importance of language for interpreting experiences. However, as demonstrated in our experiments, the type of language matters. In experiment 2 , returning to our opening example, we found learning that claret and Bordeaux are one and the same had nothing to do with learning accuracy $(r=-.05)$. Acquiring specific sensory language that aficionados can use to encode their experience is necessary for learning to occur.

\section{Implications}

Teaching aficionados how to learn about the sensory aspects of wine might provide them with more confidence in their ability to choose wines that match their own preferences. Marketers can also benefit by developing a more learned customer base, framing preferences in sensory attributes more favorably toward their particular wine. The challenge in promoting hedonic product learning is to make the perceptual/conceptual integration "fun" for the aficionados so it does not seem like work and detract from their 
hedonistic enjoyment. Short of being able to actively direct their learning in a presentation session, marketers can engage and direct the aficionados' learning through multisensory advertising. We note that this type of advertising can work as establishing a "drama" that pulls consumers into the action it portrays, encouraging comparisons between the sensory language and their own perceptual experience.

\section{Future Research and Limitations}

The traditional way of viewing learning is that different types of knowledge develop at approximately the same rate, in more or less a linear fashion, driven by motivation or involvement in the product. This article demonstrates that knowledge can be asymmetrical, and that can affect how (and if) expertise is developed. We focused on when the asymmetry is favored toward perceptual experience. With wine, and for other hedonic experiences that are readily available (and affordable), there is most likely a larger consumer base with this type of asymmetry. However, there may be cases when the reverse is true, where the consumer has attained conceptual knowledge but lacks perceptual experience with the product. In that situation, for consumers to be able to appreciate their direct experiences, they may need to bridge their learning with perceptual knowledge.

The majority of research on consumer learning has used conceptual measures to indicate level of expertise, such as number of brands recalled. Our research used a performance-based measure of expertise, which draws on both perceptual and conceptual knowledge. An important issue is to what extent our results apply to other product categories. This performance measure may be most appropriate for hedonic experiential products. Future research might investigate the boundary conditions of our findings.

\section{REFERENCES}

Alba, Joseph W. and J. Wesley Hutchinson (1987), "Dimensions of Consumer Expertise," Journal of Consumer Research, 13 (March), 411-42.

Braun, Kathryn A. (1999), "Postexperience Advertising Effects on Consumer Memory," Journal of Consumer Research, 25 (March), 319-34.

Chollet, Sylvie and Dominique Valentin (2000), "Le Degré d'Expertise a-t-il une Influence sur la Perception Olfactive? Quelques Eléments de Réponse dans le Domaine du Vin," L'Anne Psychologique, 100, 11-36.

Deighton, John (1984), "The Interaction of Advertising and Evidence," Journal of Consumer Research, 11 (December), 763-70.

Deighton, John, Daniel Romer, and Josh McQueen (1989), "Using Drama to Persuade," Journal of Consumer Research, 16 (December), 335-43.

Einhorn, Hillel J. and Robin M. Hogarth (1987), "Decision Making: Going Forward in Reverse," Harvard Business Review, 65 (January-February), 66-70.

Elder, Ryan S. and Aradhna Krishna (2010), "The Effects of Ad- vertising Copy on Sensory Thoughts and Perceived Taste," Journal of Consumer Research, 36 (February), 748-56.

Goode, James (2007), "Wine and the Brain," in Questions of Taste: The Philosophy of Wine, ed. Barry C. Smith, New York: Oxford University Press, 79-98.

Guo, Jianzeng and Aike Guo (2005), "Crossmodal Interactions between Olfactory and Visual Learning in Drosophila," Science, 309 (July), 307-10.

Hirschman, Elizabeth C. (1980), "Attributes of Attributes and Layers of Meaning," in Advances in Consumer Research, Vol. 7, ed. Jerry C. Olson, Ann Arbor, MI: Association for Consumer Research, 7-12.

Hoch, Stephen J. (2007), "When There's No Salesperson: The Value of a Consumption Vocabulary," Design Management Review, 18 (2), 77-84.

Hoch, Stephen J. and John Deighton (1989), "Managing What Consumers Learn from Experience," Journal of Marketing, 53 (April), 1-20.

Hoegg, Joandrea and Joseph W. Alba (2007), “Taste Perception: More than Meets the Tongue," Journal of Consumer Research, 33 (March), 490-98.

Hope, Jonathan and Pierre-Louis Patoine (2009), "Does a Glass of White Wine Taste Like a Glass of Domain Sigalas Santorini Asirtiko Athiri 2005? A Biosemiotic Approach to Wine-Tasting," Biosemiotics, 2 (1), 65-76.

Hughson, Angus L. (2003), "Wine Expertise: Current Theories and Findings regarding Its Nature and Bases," Food Australia, 55 (5), 193-96.

Hutchinson, J. Wesley and Joseph W. Alba (1991), "Ignoring Irrelevant Information: Situational Determinants of Consumer Learning," Journal of Consumer Research, 18 (December), $325-46$.

Hutchinson, J. Wesley and Eric M. Eisenstein (2008), "Consumer Learning and Expertise," in Handbook of Consumer Psychology, ed. Curtis P. Haugtvedt, Paul M. Herr, and Frank R. Kardes, New York: Taylor \& Francis, 103-32.

Johnson, Eric J. and J. Edward Russo (1984), "Product Familiarity and Learning New Information," Journal of Consumer Research, 11 (June), 542-50.

Lawless, Harry T. (1984), "Flavor Description of White Wine by Expert and Nonexpert Wine Consumers," Journal of Foodscience, 49 (January), 120-23.

Lockshin, Larry and Tony Spawton (2001), "Using Involvement and Brand Equity to Develop a Wine Tourism Strategy," International Journal of Wine Marketing, 13 (1), 72-81.

Melcher, Joseph M. and Jonathon W. Schooler (1996), "The Misrememberance of Wines Past: Verbal and Perceptual Expertise Mediate Verbal Overshadowing Effects," Journal of Memory and Language, 35 (April), 231-45.

(2004), "Perceptual and Conceptual Training Mediate the Verbal Overshadowing Effect in an Unfamiliar Domain," Memory and Cognition, 32 (4), 618-31.

Mitchell, Andrew A. and Peter A. Dacin (1996), "The Assessment of Alternative Measures of Consumer Expertise," Journal of Consumer Research, 23 (December), 219-39.

Miyake, Naomi and Donald A. Norman (1979), "To Ask a Question, One Must Know Enough to Know What Is Not Known," Journal of Verbal Learning and Verbal Behavior, 18, 357-64.

Noble, Ann C., Rich A. Arnold, John Buechsenstein, E. Jane Leach, Janice O. Schmidy, and Peter M. Stern (1987), "Modification of a Standardized System of Wine Aroma Terminology," American Journal of Enology and Viticulture, 38 (2), 143-46. 
Park, C. Whan, David L. Mothersbaugh, and Lawrence Feick (1994), "Consumer Knowledge Assessment," Journal of Consumer Research, 21 (June), 71-83.

Shapiro, Stewart and Mark T. Spence (2002), "Factors Affecting Encoding, Retrieval, and Alignment of Sensory Attributes in a Memory-Based Brand Choice Task," Journal of Consumer Research, 28 (March), 603-18.

Solomon, Gregg E. (1997), "Conceptual Change and Wine Expertise," Journal of the Learning Sciences, 6 (1), 41-60.

West, Patricia M., Christina L. Brown, and Stephen J. Hoch (1996),
"Consumption Vocabulary and Preference Formation," Journal of Consumer Research, 23 (September), 120-35.

Whorf, Benjamin L. (1956), Language, Thought and Reality: Selected Writings, ed. John B. Carroll, Boston: Cambridge Technology Press.

Zaichkowsky, Judith L. (1985), "Familiarity: Product Use, Involvement, or Expertise," in Advances in Consumer Research, Vol. 12, ed. Elizabeth C. Hirschman and Morris B. Holbrook, Provo, UT: Association for Consumer Research, 296-99. 